\section{Aplicação do Índice de Qualidade de Vida Humana (IQVH) nas regiões metropolitanas do Brasil}

\section{Glauco José de Matos Umbelino*}

Essa pesquisa foi desenvolvida visando contribuir com as discussões em torno da temática "qualidade de vida", realizadas no GT População, Espaço e Ambiente, da Associação Brasileira de Estudos Populacionais - Abep.

Procurou-se operacionalizar a referida temática, por meio da aplicação do Índice de Qualidade de Vida Humana (IQVH), desenvolvido pelo Centro de Desenvolvimento e Planejamento Regional - Cedeplar, da Universidade Federal de Minas Gerais - UFMG, nos municípios integrantes das nove regiões metropolitanas (RMs) originais do IBGE, em 1991 e 2000, observando-se as principais mudanças ocorridas nesse período.

O IQVH é formado por cinco indicadores (qualidade da habitação, condições de vida, renda, saúde e segurança ambiental e serviços sanitários) e mensura aspectos relacionados ao desenvolvimento humano e à qualidade do ambiente construído. As variáveis de desenvolvimento humano são as mesmas usadas no cálculo do índice de Desenvolvimento Humano Municipal (IDH-M), separadas em um indicador de qualidade de vida e outro de renda. As variáveis de qualidade da habitação, serviços sanitários e segurança ambiental refletem a qualidade do ambiente construído no que se refere ao provimento de condições adequadas a uma vida humana saudável. Já aquelas de saúde ambiental exprimem a incidência de doenças causadas por fatores ambientais (ar e água).

De acordo com o limite de investigação estabelecido, esta pesquisa deve ser considerada uma aproximação teórica, metodológica e empírica da temática exposta, realizada em dois momentos complementares, de forma sintética e objetiva. No primeiro, foi feita uma interpretação de cunho interdisciplinar, abordando noções de meio ambiente, urbanização e crescimento populacional no Brasil, além de algumas considerações sobre "qualidade de vida" e o grande desafio de sua mensuração. O segundo momento representa cartograficamente o Índice de Qualidade de Vida Humana, com sua aplicação nas RMs, em 1991 e 2000, e comparações das principais mudanças ocorridas neste período.

\section{Fontes de dados}

Foram utilizadas informações da pesquisa desenvolvida pelo Cedeplar/UFMG, no projeto Biodiversidade, População e Economia, associadas com a pesquisa produzida pelo Laboratório de Estudos Territoriais - Leste, da UFMG, no projeto intitulado Migração e Urbanização Descentralizada no Brasil Contemporâneo.

Para a elaboração do IQVH, foram extraídos dados dos Censos Demográficos de 1991 e 2000, do Sistema de Informações sobre Mortalidade - SIM e do Atlas do Desenvolvimento Humano no Brasil - 2000. A base municipal para a produção dos mapas temáticos foi a malha digital do Brasil em 2000, fornecida pelo IBGE.

\section{Resultados}

Até o momento, esta pesquisa resultou na realização de uma monografia de graduação, duas apresentações orais em eventos acadêmicos ligados a estudos populacionais e em um artigo vencedor, na categoria estudante, do prêmio "20 Anos do

\footnotetext{
* Geógrafo, doutorando em Demografia pelo Centro de Desenvolvimento e Planejamento Regional - Cedeplar, da Universidade Federal de Minas Gerais - UFMG.
} 
Programa de Pós-Graduação em Demografia - Cedeplar".

O IQVH permite analisar a discrepância social, econômica e ambiental existente entre as RMs brasileiras. Os dados indicam que, ao mesmo tempo em que o índice melhorou na maioria das localidades, as desigualdades aumentaram entre $1991 \mathrm{e}$ 2000. Pretende-se explorar melhor os resultados do IQVH e principalmente de seus cinco indicadores, além de atualizá-los para um período mais recente, quando todos os dados necessários para sua elaboração estiverem disponíveis.

O IQVH teve boa resposta quando aplicado nas RMs, sendo que as disparidades intrametropolitanas condizem muitas vezes com os dados socioeconômicos utilizados em outras pesquisas. Quando são observados os mapas das $\mathrm{RMs}$, nota-se que, de maneira geral, quanto mais meridional é a $\mathrm{RM}$, melhores são os valores referentes à qualidade de vida da população.

Outra tendência é que nas RMs analisadas percebe-se, grosso modo, uma expansão no sentido centro-periferia, sendo que esta periferia é preenchida por pequenos focos habitados por uma população diversificada (ricos e classe média), mas com alto padrão de vida e elevado $\mathrm{IQVH}$, contracenando com a imensa população residente em áreas com baixo padrão de vida e reduzido IQVH. Este fato sugere reflexões sobre o fenômeno da metropolização que ocorreu nos últimos anos em uma escala maior do que as administrações municipais e estaduais conseguiram suportar.

Decompondo o IQVH, resultados instigantes ainda estão para ser explorados, pois o que mais contribuiu para o aumento do índice, entre 1991 e 2000, foi o indicador de serviços sanitários e, em contrapartida, o que mais influenciou na sua diminuição em muitos locais foram os indicadores de qualidade da habitação e saúde e segurança ambiental. Este último aborda a mortalidade por doenças respiratórias e parasitárias, fortes instrumentos de estimativas indiretas da qualidade do ar e água que a população usufrui, bem como a mortalidade por causas externas (homicídios e acidentes de trânsito), fato cada vez mais alarmante nas grandes cidades e regiões metropolitanas, principalmente na população jovem, maior alvo destes tipos de óbitos.

Um exemplo da aplicação dos resultados desta pesquisa é sua utilização pelas administrações municipais e entidades da sociedade civil como indicadores para avaliar a qualidade de vida de suas populações, tomando como opção metodológica os instrumentos desenvolvidos neste trabalho. Os resultados podem não refletir a verdadeira realidade do local, mas valem como a tentativa de aproximação dessa realidade a partir de dados quantitativos $e$ qualitativos.

Com base nos resultados e leituras realizadas, destaca-se a necessidade de implementação de princípios e diretrizes de sustentabilidade, bem como a monitoração dos elementos que caracterizam o ambiente urbano, tornando pesquisas nessa área cada vez mais evidentes, à medida que se ampliam os problemas ambientais, econômicos e sociais responsáveis pelo declínio da "qualidade de vida" nas cidades. Desta forma, os indicadores tornam-se instrumentos fundamentais para promover o conhecimento e a informação necessários para a compreensão das especificidades e questões presentes nos centros urbanos, sendo que sua utilização torna-se cada vez mais crescente nos órgãos planejadores e administrativos.

Recebido para publicação em 06/03/2007. Aceito para publicação em 12/11/2007. 